\title{
H-V (Hydrogen-Vanadium)
}

\section{H. Okamoto}

The V-H diagram shown in Fig. 1 is not accepted, but is quoted from $[91 \mathrm{Mog}]$ for reference purposes only. This diagram covers wider temperature and composition ranges than the diagram shown in [Massalski2]. However, numerous phase rule violations and thermodynamically improbable features are involved (see [910ka1], [910ka2], [920ka1], and [920ka2]). Apparently, substantial modifications are needed.

\section{Cited References}

91Fuk: Y. Fukai, Kotai Butsuri, 26(9), 592-609(1991) in Japanese.
91Mog: K. Mogi, MS thesis, Chuo Univ., (1991); quoted from [91Fuk]. 910ka1: H. Okamoto, J. Phase Equilibria, 12(6), 623-643(1991).

91Oka2: H. Okamoto and T.B. Massalski, J. Phase Equilibria, 12(2), 148-168(1991).

92Oka1: H. Okamoto and T.B. Massalski, submitted toJ. Phase Equilibria (1992).

92Oka2: H. Okamoto and T.B.Massalski, submitted to J. Phase Equilibria (1992).

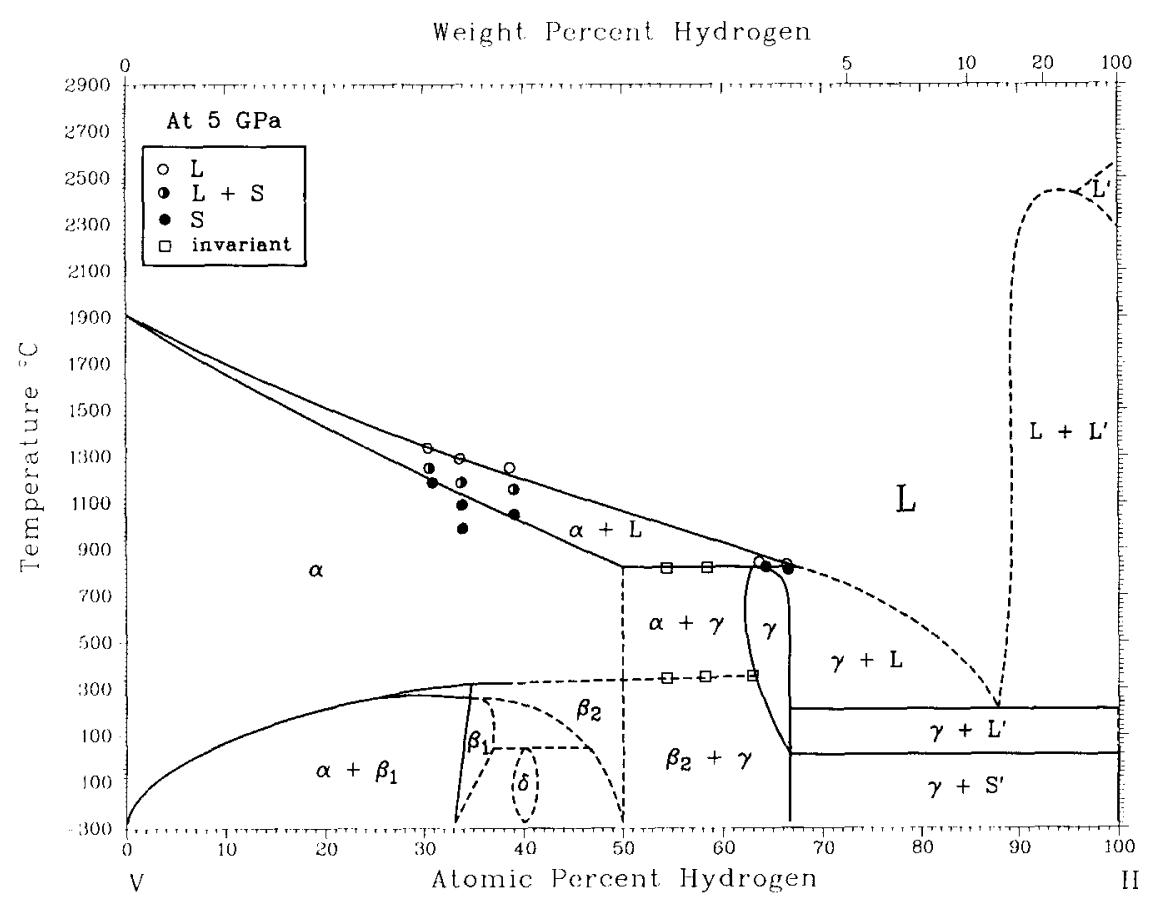

Fig. 1 V-H phase diagram.

\section{Sc-Si (Scandium-Silicon)}

\section{H. Okamoto}

The Sc-Si phase diagram in [Massalski2] was proposed by [86Gok]. Because no experimental data were available on any liquidus boundary, a similarity to the $\mathrm{Y}-\mathrm{Ge}$ and $\mathrm{Sc}-\mathrm{Ge}$ systems was assumed. Three compounds- $\mathrm{Sc}_{5} \mathrm{Si}_{3}, \mathrm{ScSi}$, and $\mathrm{Sc}_{3} \mathrm{Si}_{5}$ were reported to exist.
[88Ere] investigated this system by means of DTA, metallography, and XRD. The Sc-Si phase diagram shown in Fig. 1 is based on this result with minor modifications that take into account thermodynamic consistency as described by [91Oka2] (symmetry of the liquidus, sign of the curvature, initial slope, etc.). The melting 